Article

\title{
Various Allotropes of Diamond Nanoparticles Generated in the Gas Phase during Hot Filament Chemical Vapor Deposition
}

\author{
Hwan-Young Kim ${ }^{1}$, Da-Seul Kim ${ }^{1}$, Kun-Su Kim ${ }^{1}$ and Nong-Moon Hwang ${ }^{1,2, *(1)}$ \\ 1 Department of Materials Science and Engineering, Seoul National University, 1 Gwanak-ro, Gwanak-gu, \\ Seoul 08826, Korea; welcome777@snu.ac.kr (H.-Y.K.); daseul@snu.ac.kr (D.-S.K.); lstatsl@snu.ac.kr (K.-S.K.) \\ 2 Research Institute of Advanced Materials, 599 Gwanak-ro, Gwanak-gu, Seoul 08826, Korea \\ * Correspondence: nmhwang@snu.ac.kr
}

Received: 22 November 2020; Accepted: 10 December 2020; Published: 14 December 2020

\begin{abstract}
Diamond nanoparticles have been synthesized using various methods. Nanodiamonds generated in the gas phase were captured on the membrane of a transmission electron microscope grid during a hot filament chemical vapor deposition (HFCVD) diamond process. In total, $\sim 600$ nanoparticles, which were captured for $10 \mathrm{~s}$ in six conditions of the capture temperatures of $900{ }^{\circ} \mathrm{C}, 600{ }^{\circ} \mathrm{C}$ and $300{ }^{\circ} \mathrm{C}$ and the gas mixtures of $1 \% \mathrm{CH}_{4}-99 \% \mathrm{H}_{2}$ and $3 \% \mathrm{CH}_{4}-97 \% \mathrm{H}_{2}$, were analyzed for phase identification using high-resolution transmission electron microscopy and fast Fourier transformation. Hexagonal diamond, i-carbon, n-diamond, and cubic diamond were identified. The observation of two or more carbon allotropes captured on the same membrane suggested their coexistence in the gas phase during HFCVD. The crystal structure of carbon allotropes was related to the size of the nanodiamond. The crystal structure of the nanoparticles affected the crystal structure of diamond deposited for $8 \mathrm{~h}$. Confirmation of various carbon allotropes provides new insight into the nanodiamond synthesis in the gas phase and the growth mechanism of HFCVD diamond.
\end{abstract}

Keywords: HFCVD; nanodiamonds; cubic diamond; n-diamond; hexagonal diamond; i-carbon

\section{Introduction}

Diamond has been synthesized using high-pressure/high-temperature methods [1], and plasmadischarge-stimulated chemical vapor deposition (CVD) [2,3] and hot filament CVD (HFCVD) [4]. In addition to the synthesis of diamond bulks or films, nanodiamonds could be synthesized by detonation [5], laser ablation [6], plasma-assisted CVD [7], ion irradiation of graphite [8], electron irradiation of carbon onions [9], ball milling of high-pressure/high-temperature diamond [10] and ultrasound cavitation [11]. Detonation, laser ablation, and ball milling methods are used commercially, with detonation being the most common approach. Nanodiamonds are applied to biological studies, medical diagnostics and quantum technologies because the optical centers in diamond offer well-defined optical transitions and long-lived spin quantum states [12-14]. However, detonation nanodiamonds tend to be agglomerated and to include impurity defects, making it difficult for them to be applied to photoluminescence $[15,16]$.

For applications of nanodiamonds, it is necessary to synthesize non-agglomerated high quality nanodiamonds. Park et al. [17] succeeded to confirm the generation of non-agglomerated diamond nanoparticles in the gas phase under the synthesis condition of diamond films by HFCVD. Their result showed that non-agglomerated high quality nanodiamonds can be synthesized using a HFCVD reactor. As the extension of their work, here we studied the crystal structure of nanodiamonds and how the crystal structure is affected by the processing condition. For this, we captured nanodiamonds 
generated in the gas phase on a graphene membrane of a transmission electron microscope (TEM) grid during HFCVD using a capturing apparatus under various processing conditions. The analysis of the nanoparticles by high resolution TEM (HR-TEM) and fast Fourier transformation (FFT) revealed four carbon allotropes: i-carbon, hexagonal diamond, n-diamond, and cubic diamond. By comparing the size distribution of the captured nanoparticles at capture temperatures of $900{ }^{\circ} \mathrm{C}, 600{ }^{\circ} \mathrm{C}$ and $300{ }^{\circ} \mathrm{C}$ at the gas mixtures of $1 \% \mathrm{CH}_{4}-99 \% \mathrm{H}_{2}$ and $3 \% \mathrm{CH}_{4}-97 \% \mathrm{H}_{2}$, we studied the relation between the size of nanodiamonds and the crystal structure. In addition, the crystal structure of the nanoparticles was shown to be related to the crystal structure of the deposited diamond.

\section{Materials and Methods}

\subsection{Preparation of Nanoparticles}

The HFCVD reactor with the capturing system is shown schematically in Figure 1 . The filament consisted of three tungsten wires of $0.5 \mathrm{~mm} \varnothing$, which were twisted into a nine-turn coil of $8 \mathrm{~mm}$. The filament temperature was $2100{ }^{\circ} \mathrm{C}$ and the reactor pressure was 20 Torr. $\mathrm{CH}_{4}$ and $\mathrm{H}_{2}$ were supplied as a gas mixture at 1 standard cubic centimeter per minute $(\mathrm{sccm})$ and $99 \mathrm{sccm}$ or at $3 \mathrm{sccm}$ and $97 \mathrm{sccm}$, respectively, using a mass flow controller.

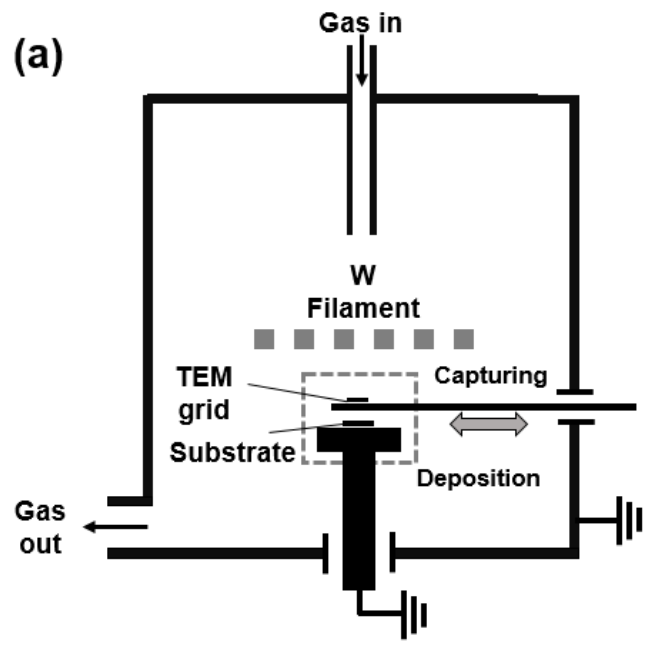

(b)



Figure 1. Schematics of (a) the hot filament chemical vapor deposition (HFCVD) reactor with the apparatus for capturing carbon nanoparticles on the graphene membrane of the TEM grid and (b) the capturing apparatus.

When nanoparticles were captured on the membrane of a TEM grid at high temperature such as $900^{\circ} \mathrm{C}$, capturing was difficult due to the thermal damage or etching of carbon by atomic hydrogen. Several membranes were tested. The SiO membrane (SiO Type-A, Ted Pella, Inc., Redding, CA, USA) proved very vulnerable to thermal damage above $\sim 600{ }^{\circ} \mathrm{C}$. The carbon membrane (ultrathin carbon type-A; Ted Pella, Inc.) was easily etched away at a capture temperature of $900{ }^{\circ} \mathrm{C}$. After many trials, we determined that a graphene membrane was most suitable for nanoparticle capture, as it is conducting and can withstand thermal damage over the capture time of $10 \mathrm{~s}$. Additionally, some of the graphene membrane remained unetched within the $10 \mathrm{~s}$ timeframe, which made it possible to capture diamond nanoparticles even at $900{ }^{\circ} \mathrm{C}$.

A graphene membrane (6-8 layers of graphene film; Ted Pella, Inc.) was used to capture the diamond nanoparticles. A schematic of the capturing apparatus is shown in Figure 1. The capturing apparatus could be pushed to the capture zone as needed and retracted back toward the chamber wall. The distance between the hot filament and the capture zone was varied as $6 \mathrm{~mm}, 30 \mathrm{~mm}$ and $50 \mathrm{~mm}$, where the temperature of the capture zone was, respectively, $900 \pm 50{ }^{\circ} \mathrm{C}, 600 \pm 50{ }^{\circ} \mathrm{C}$ and $300 \pm 50{ }^{\circ} \mathrm{C}$. Before capturing, the filament was carburized at $2100{ }^{\circ} \mathrm{C}$ for $24 \mathrm{~h}$ at $1 \% \mathrm{CH}_{4}-99 \% \mathrm{H}_{2}$ 
when capturing was conducted at $1 \% \mathrm{CH}_{4}-99 \% \mathrm{H}_{2}$ and at $3 \% \mathrm{CH}_{4}-97 \% \mathrm{H}_{2}$ when capturing was conducted at $3 \% \mathrm{CH}_{4}-97 \% \mathrm{H}_{2}$. To increase the reproducibility of the experiments, capturing was conducted after supplying the gas mixture of $\mathrm{CH}_{4}$ and $\mathrm{H}_{2}$ for $30 \mathrm{~min}$ at the filament temperature of $2100{ }^{\circ} \mathrm{C}$. The quartz holder loaded with the TEM grid was pushed to the capture zone, and the grid was exposed for a capturing time of $10 \mathrm{~s}$. After that, the quartz holder was pulled from the capture zone to the chamber wall. Captured diamond nanoparticles were analyzed by HR-TEM (JEM-2100F; JEOL Ltd., Tokyo, Japan). The grid was placed on the quartz holder, and the holder was connected to the capturing apparatus.

\subsection{Analysis of Nanoparticles}

Some captured carbon nanoparticles were polycrystalline or aggregated. Most of them were single crystals, which were used to identify the phase. From the FFT image of each nanoparticle, lattice parameters and the angle between lattices were determined, based on Joint Committee on Powder Diffraction Standards (JCPDS) data of the reported carbon allotropes. In identifying the phase of single-crystalline carbon nanoparticles, we encountered two difficulties. The first was the coexistence of allotropes of carbon nanoparticles, and the second was that the different carbon allotropes have the same d-spacing value. As a result, several d-spacing values and lattice angles of the carbon nanoparticles needed to be evaluated. Out of nanoparticles captured on the membrane at each temperature of $900{ }^{\circ} \mathrm{C}, 600^{\circ} \mathrm{C}$ and $300^{\circ} \mathrm{C}, \sim 100$ nanoparticles were chosen to determine the size and d-spacing by DigitalMicrograph (Gatan, Inc., Pleasanton, CA, USA). One hundred fifty d-spacings were obtained from $\sim 100$ nanoparticles, which was repeated 6 times for 6 experimental conditions of capture temperatures of $900 \pm 50{ }^{\circ} \mathrm{C}, 600 \pm 50{ }^{\circ} \mathrm{C}$ and $300 \pm 50{ }^{\circ} \mathrm{C}$ and the gas mixtures of $1 \% \mathrm{CH}_{4}-99 \%$ $\mathrm{H}_{2}$ and $3 \% \mathrm{CH}_{4}-97 \% \mathrm{H}_{2}$. The d-spacings were classified from JCPDS of the reported carbon allotropes. All lattice angles of the reported carbon structures, from i-carbon to cubic diamond, were used to identify the crystal structure of individual nanoparticles.

\subsection{Current Measurement}

Using a picoammeter (model 6487; Keithley Instruments, Cleveland, OH, USA), we measured the current between the substrate and the ground, which would represent the density of electrons emitted from the hot filament. The feedthrough, which was connected to the picoammeter, was placed $30 \mathrm{~mm}$ below the filament. The number density of nanoparticles captured on the graphene membrane was measured by ImageJ software (ImageJ, National Institutes of Health, Bethesda, MD, USA).

\subsection{Deposition of Diamond Particles}

Cubic diamond and n-diamond allotropes were dominant in the gas mixture of $1 \% \mathrm{CH}_{4}-99 \% \mathrm{H}_{2}$, whereas nanoparticles of i-carbon allotropes were more dominant in the gas mixture of $3 \% \mathrm{CH}_{4}-97 \% \mathrm{H}_{2}$. The deposition behavior of diamond depends on which allotropic nanoparticle was dominant in the gas phase. To study this, diamond particles were deposited for $8 \mathrm{~h}$ on Si substrates under filament and substrate temperatures of $2100^{\circ} \mathrm{C}$ and $900^{\circ} \mathrm{C}$, respectively. To observe individual diamond particles, the $\mathrm{Si}$ substrate was not pretreated because the pretreatment tends to produce films. The Si substrate was placed $6 \mathrm{~mm}$ below the hot filament. The microstructure of the deposited diamond particles was observed by field-emission scanning electron microscopy (FE-SEM; SU70; Hitachi Ltd., Tokyo, Japan).

\section{Results and Discussion}

\subsection{Identification of Nanoparticles}

After analyzing $~ 600$ captured nanoparticles, we could identify four kinds of carbon allotropes: i-carbon, hexagonal diamond, n-diamond and cubic diamond. As an example, Figure 2a shows a TEM image of nanoparticles on the graphene membrane of the $\mathrm{Cu}$ grid for a capture time of $10 \mathrm{~s}$ and capture temperature of $900{ }^{\circ} \mathrm{C}$, using a filament temperature of $2100{ }^{\circ} \mathrm{C}$ and a gas mixture of $1 \% \mathrm{CH}_{4}-99 \%$ 
$\mathrm{H}_{2}$. Figure 2a shows that nanoparticles of $2 \sim 7 \mathrm{~nm}$ are distributed randomly. The HR-TEM image in Figure $2 b$ shows the magnified image of the white square in Figure 2a. Figure $2 c$ is the magnified image of the nanoparticle in the white circle of Figure $2 b$, showing the lattice image of the nanoparticle with a diameter of $\sim 4.9 \mathrm{~nm}$. The FFT image recorded from the nanoparticle in Figure 2c is shown in Figure $2 \mathrm{~d}$. The FFT image in Figure 2d shows the (200) forbidden plane, indicating that the nanoparticle has an n-diamond structure. This is the way that observed nanoparticles were identified and classified.
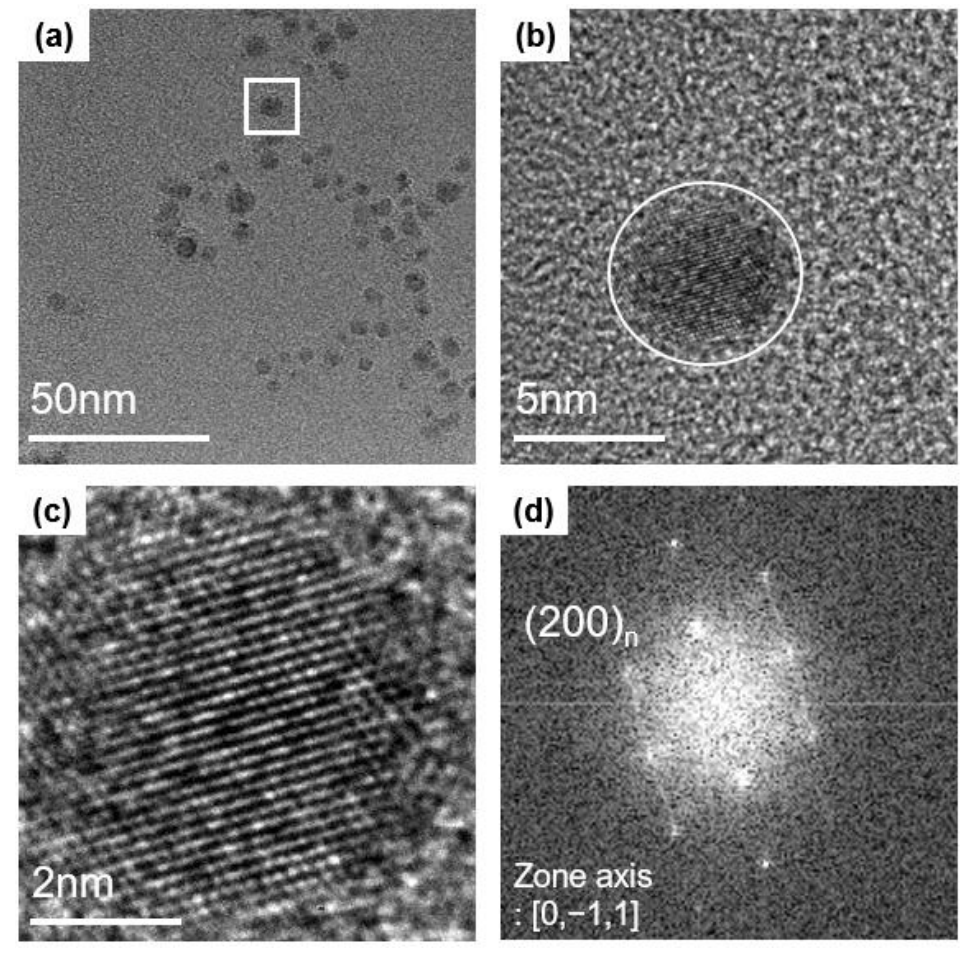

Figure 2. (a) TEM image of nanoparticles captured on the graphene membrane of the TEM Cu grid with a capture time of $10 \mathrm{~s}$, (b) high resolution TEM (HR-TEM) image of the white square in (a), (c) a higher magnification of the nanoparticle in the white circle of $(\mathbf{b}, \mathbf{d})$ the fast Fourier transformation (FFT) image of (c).

To characterize the phase of the nanoparticles, both d-spacings and lattice angles determined from the FFT image were compared with the reported values of carbon allotropes. The observed nanoparticles were classified into four carbon allotropes: i-carbon, hexagonal diamond, n-diamond, and cubic diamond, as shown in Figure 3, respectively. The nanoparticle in Figure 3a was captured for $10 \mathrm{~s}$ at $900{ }^{\circ} \mathrm{C}$ with a filament temperature at $2100{ }^{\circ} \mathrm{C}$ and gas mixture of $3 \% \mathrm{CH}_{4}-97 \% \mathrm{H}_{2}$. The FFT image in Figure 3a shows the single-crystalline cubic phase diamond along the $<110>$ zone axis. Vora et al. [18] analyzed an i-carbon film that contained an unknown cubic phase having a lattice parameter of $4.25 \AA$; they assigned d-spacings of 2.43 and $2.12 \AA$ of the phase to the (111) and (200) planes, respectively. This phase is called i-carbon [19-21]; d-spacings of 2.42 and $2.10 \AA$ of the nanoparticle in Figure 3a were assigned, respectively, to the (111) and (200) planes of the cubic phase with a lattice parameter $4.2 \AA$, which are nearly the same as the spacings reported by Vora et al. [18]. The observed i-carbon nanoparticles showed a d-spacing range of 2.36-2.54 $\AA$. As a result, there was variation in the lattice parameter over the range of 4.1-4.4 $\AA$. Additionally, the lattice angles of $70^{\circ}$ and $54^{\circ}$ shown in Figure $3 a$, which are between the two (111) planes and between the (111) and (200) planes, respectively, matched with those of i-carbon. 

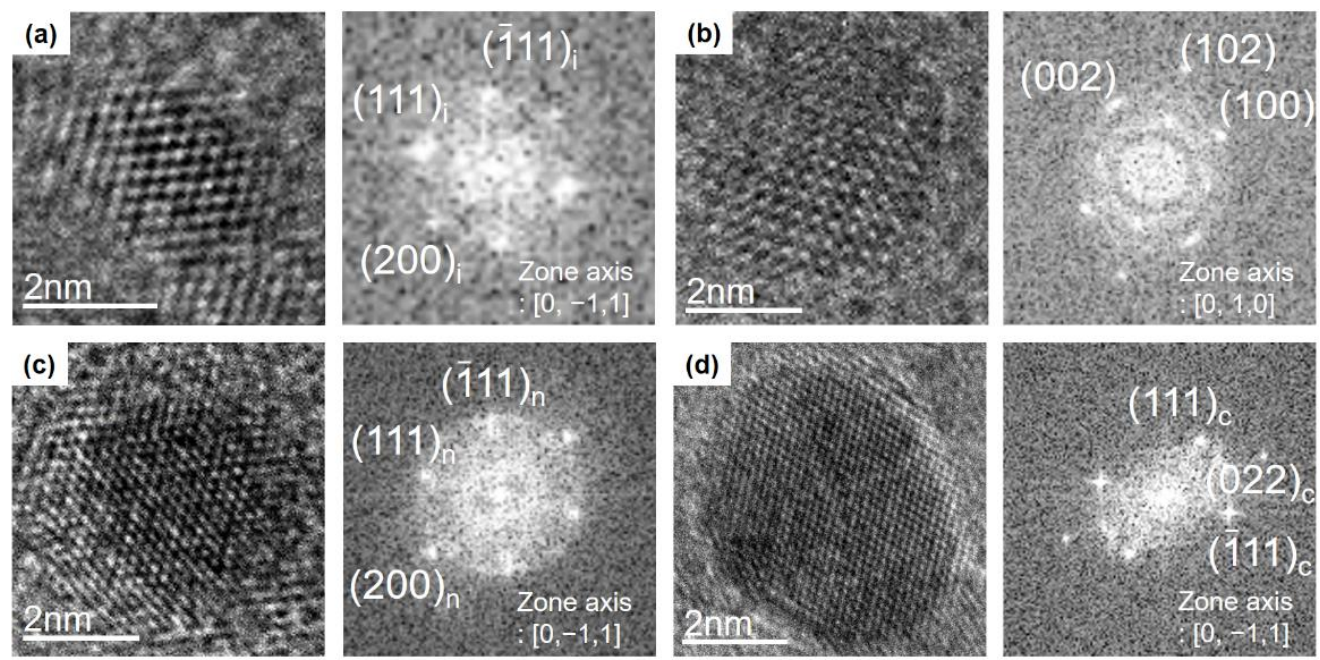

Figure 3. HR-TEM and FFT images of (a) i-carbon at $3 \% \mathrm{CH}_{4}-97 \% \mathrm{H}_{2},(\mathbf{b})$ hexagonal diamond at $1 \%$ $\mathrm{CH}_{4}-99 \% \mathrm{H}_{2}$, (c) n-diamond at $3 \% \mathrm{CH}_{4}-97 \% \mathrm{H}_{2}$, and (d) cubic diamond at $1 \% \mathrm{CH}_{4}-99 \% \mathrm{H}_{2}$.

The nanoparticle in Figure $3 \mathrm{~b}$ was captured at $300^{\circ} \mathrm{C}$ with the filament temperature at $2100{ }^{\circ} \mathrm{C}$ and the gas mixture of $1 \% \mathrm{CH}_{4}-99 \% \mathrm{H}_{2}$. The FFT image in Figure $3 \mathrm{~b}$ shows the single-crystalline hexagonal diamond along the $<100>$ zone axis. HR-TEM and FFT images show the (100), (002), and (102) lattice planes of hexagonal diamond. The lattice angles of $90^{\circ}$ and $43^{\circ}$ in Figure $3 \mathrm{~b}$, which are between the (100) and (002) planes and between the (002) and (102) planes, respectively, matched those of a hexagonal diamond structure (JCPDS No.19-0268).

The conditions used to capture the nanoparticle shown in Figure $3 \mathrm{c}$ were the same as those in Figure 3a, in which a gas mixture of $3 \% \mathrm{CH}_{4}-99 \% \mathrm{H}_{2}$ was supplied. The FFT image in Figure $3 \mathrm{c}$ shows a single-crystalline n-diamond along the $<110>$ zone axis. HR-TEM and FFT images display the (111) and (200) lattice planes of n-diamond. The lattice angles of $70^{\circ}$ and $54^{\circ}$ in Figure $3 c$, which are between the two (111) planes and between (111) and (200) planes, respectively, matched those of n-diamond (JCPDS No.43-1104).

The nanoparticle in Figure $3 \mathrm{~d}$ was captured at $900^{\circ} \mathrm{C}$ with the filament temperature at $2100{ }^{\circ} \mathrm{C}$ and the gas mixture of $1 \% \mathrm{CH}_{4}-99 \% \mathrm{H}_{2}$. The FFT image in Figure $3 \mathrm{~d}$ shows a single-crystalline cubic diamond along the $\langle 110>$ zone axis and the two (111) planes and the (220) plane of cubic diamond (Fd3m). HR-TEM and FFT images show d-spacings of 2.06 and $1.25 \AA$, which correspond to the (111) and (220) planes of cubic diamond, respectively. The lattice angles of $70^{\circ}$ and $35^{\circ}$ in Figure $3 \mathrm{~d}$, which are between the two (111) planes and between the (111) and (220) planes, respectively, match with those of cubic diamond (JCPDS No.6-0675).

\subsection{Captured Nanoparticles under Various Processing Conditions}

We tried to investigate the dependence of the crystal structure of captured nanoparticles on the capture temperature and the methane concentration. For this, we analyzed the crystal structure of the captured nanoparticles at $900{ }^{\circ} \mathrm{C}, 600{ }^{\circ} \mathrm{C}$ and $300{ }^{\circ} \mathrm{C}$ on the gas mixture of $1 \% \mathrm{CH}_{4}-99 \% \mathrm{H}_{2}$ and $3 \%$ $\mathrm{CH}_{4}-97 \% \mathrm{H}_{2}$. Figure $4 \mathrm{a}-\mathrm{f}$ show the number of nanoparticles with given d-spacing values, respectively, at $1 \% \mathrm{CH}_{4}-99 \% \mathrm{H}_{2}$ and $3 \% \mathrm{CH}_{4}-97 \% \mathrm{H}_{2}$ at the filament temperature of $2100{ }^{\circ} \mathrm{C}$. The number of nanoparticles with given d-spacing values in Figure 4 was determined from $150 \mathrm{~d}$-spacing values out of $\sim 100$ nanoparticles for each membrane. The number of the d-spacing values in Figure 4 would be related with the XRD intensity of the polycrystal. The number of the d-spacing values could be used to roughly estimate the phase fraction of the nanoparticles $[18,19]$. The $\mathrm{d}$-spacing values were analyzed according to the reported values for the carbon allotrope in JCPDS. We made an approximation that the observed d-spacing would correspond to that of JCPDS if the d-spacing value coincides within $\sim 3 \%$. 

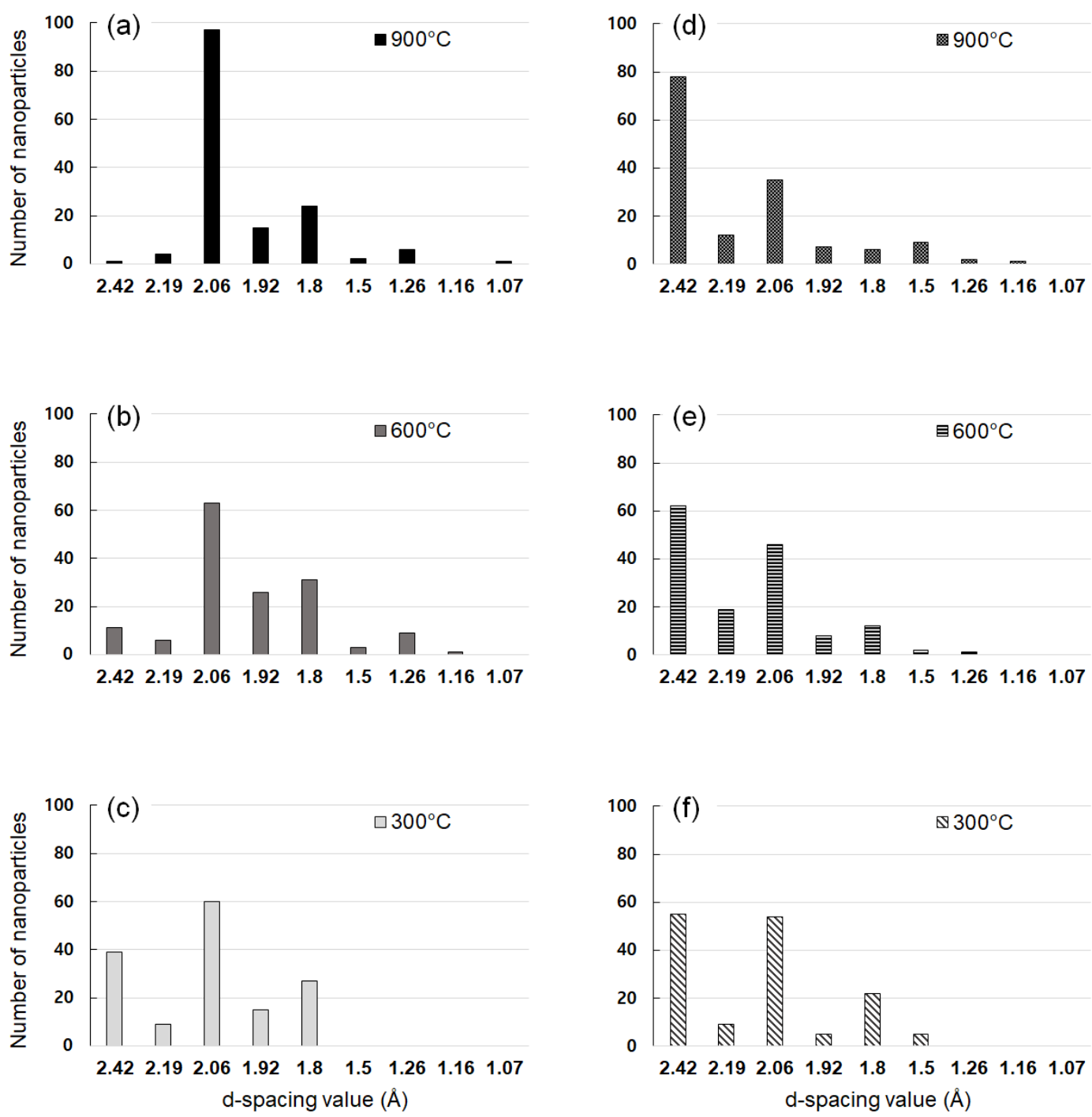

Figure 4. Number of nanoparticles with the given d-spacing values determined from $150 \mathrm{~d}$-spacing values of $\sim 100$ nanoparticles captured at (a) $1 \% \mathrm{CH}_{4}-99 \% \mathrm{H}_{2}$ and $900{ }^{\circ} \mathrm{C}$, (b) $1 \% \mathrm{CH}_{4}-99 \% \mathrm{H}_{2}$ and $600{ }^{\circ} \mathrm{C}$, (c) $1 \% \mathrm{CH}_{4}-99 \% \mathrm{H}_{2}$ and $300{ }^{\circ} \mathrm{C}$, (d) $3 \% \mathrm{CH}_{4}-97 \% \mathrm{H}_{2}$ and $900{ }^{\circ} \mathrm{C}$, (e) $3 \% \mathrm{CH}_{4}-97 \% \mathrm{H}_{2}$ and $600{ }^{\circ} \mathrm{C}$, and (f) $3 \% \mathrm{CH}_{4}-97 \% \mathrm{H}_{2}$ and $300{ }^{\circ} \mathrm{C}$.

In Figure $4 \mathrm{a}$, where the gas mixture was $1 \% \mathrm{CH}_{4}-99 \% \mathrm{H}_{2}$, nanoparticles captured at $900{ }^{\circ} \mathrm{C}$ show the number of 97 for $2.06 \AA$ and the number of 1 for $2.42 \AA$. In addition, in Figure $4 \mathrm{c}$, nanoparticles captured at $300{ }^{\circ} \mathrm{C}$ showed the number of 39 for $2.42 \AA$ and the number of 60 for $2.06 \AA$. However, in Figure $4 \mathrm{~d}$, where the gas mixture was $3 \% \mathrm{CH}_{4}-97 \% \mathrm{H}_{2}$, nanoparticles captured at $900{ }^{\circ} \mathrm{C}$ show the number of 35 for $2.06 \AA$ and the number of 78 for $2.42 \AA$. On the other hand, in Figure $4 \mathrm{f}$, nanoparticles captured at $300{ }^{\circ} \mathrm{C}$ showed the number of 55 for $2.42 \AA$ and the number of 54 for $2.06 \AA$. The number for $2.06 \AA$ at $1 \% \mathrm{CH}_{4}-99 \% \mathrm{H}_{2}$ in Figure $4 \mathrm{a}-\mathrm{c}$ is higher than that at $3 \% \mathrm{CH}_{4}-97 \% \mathrm{H}_{2}$ in Figure $4 \mathrm{~d}-\mathrm{f}$ at all capture temperatures.

At the gas mixture of $1 \% \mathrm{CH}_{4}-99 \% \mathrm{H}_{2}$, the number of nanoparticles with $2.06 \AA$ increases as the capture temperature increases. However, at the gas mixture of $3 \% \mathrm{CH}_{4}-97 \% \mathrm{H}_{2}$, the number of nanoparticles with $2.06 \AA$ decreases as the capture temperature increases. Figure $4 \mathrm{a}-\mathrm{c}$ show that at the gas mixture of $1 \% \mathrm{CH}_{4}-99 \% \mathrm{H}_{2}$, the number of cubic diamond and n-diamond increase as the capture temperature increases from $300{ }^{\circ} \mathrm{C}$ to $900{ }^{\circ} \mathrm{C}$. On the other hand, Figure $4 \mathrm{~d}-\mathrm{f}$ show that at the gas mixture of $3 \% \mathrm{CH}_{4}-97 \% \mathrm{H}_{2}$, the number of captured i-carbon nanoparticles increases as the capture temperature increases from $300{ }^{\circ} \mathrm{C}$ to $900{ }^{\circ} \mathrm{C}$. 
Table 1 compares the observed d-spacing values with those reported for cubic diamond, $\mathrm{n}$-diamond, hexagonal diamond, and i-carbon. The relative XRD intensity $\left(\mathrm{I} / \mathrm{I}_{111}\right)$ is shown for each reported d-spacing in Table 1. For n-diamond, the relative XRD intensities of (111) and (200) are 100 and 100, respectively, whereas for cubic diamond, the corresponding intensities are 100 and 0 , respectively. As mentioned earlier, the experimentally observed d-spacing of (200) indicates the existence of n-diamond. If nanoparticles show a high fraction of (111) but none of (200) in FFT images, then they would be cubic diamond. Although the ratio of the relative XRD intensity of (111) to (200) was 1 for the reported n-diamond in Table 1, the observed d-spacing ratio of (111) to (200) shown in Figure 4a was 5. The d-spacing ratio of the observed nanoparticles, which were captured at $900{ }^{\circ} \mathrm{C}$ with the filament temperature at $2100{ }^{\circ} \mathrm{C}$ and the gas mixture of $1 \% \mathrm{CH}_{4}-99 \% \mathrm{H}_{2}$, was five-fold larger than the ratio of the relative XRD intensities. This result indicates that the nanoparticles captured at $900{ }^{\circ} \mathrm{C}$ in Figure $4 \mathrm{a}$ had a fraction of cubic diamond higher than that of n-diamond.

The d-spacing of $2.42 \AA$ belongs to i-carbon, whereas the d-spacing of $2.06 \AA$ belongs to cubic diamond or $\mathrm{n}$-diamond. Therefore, a larger number of $2.06 \AA$ than that of $2.42 \AA$ indicates that cubic diamond or $n$-diamond is a major phase with i-carbon being a minor phase. Similarly, a smaller number of $2.06 \AA$ than that of $2.42 \AA$ indicates that $\mathrm{i}$-carbon is a major phase with cubic diamond or n-diamond being a minor phase. Figure 4 shows that the number of a $2.06 \AA$ d-spacing for $1 \% \mathrm{CH}_{4}-99 \%$ $\mathrm{H}_{2}$ was larger than that for $3 \% \mathrm{CH}_{4}-97 \% \mathrm{H}_{2}$; additionally, the number of nanoparticles for the $2.42-\AA$ d-spacing, which was very high for $3 \% \mathrm{CH}_{4}-97 \% \mathrm{H}_{2}$, is related to i-carbon. Thus, the nanoparticles for $3 \% \mathrm{CH}_{4}-97 \% \mathrm{H}_{2}$ consisted mainly of i-carbon, whereas those for $1 \% \mathrm{CH}_{4}-99 \% \mathrm{H}_{2}$ consisted mainly of cubic diamond or n-diamond.

\subsection{Size Dependence on the Crystal Structure of Nanoparticles}

Figure 5 shows the TEM images of nanoparticles captured under six different conditions. Figure 5a-c show nanoparticles captured, respectively, at $900{ }^{\circ} \mathrm{C}, 600{ }^{\circ} \mathrm{C}$ and $300{ }^{\circ} \mathrm{C}$ at the gas mixture of $1 \% \mathrm{CH}_{4}-99 \% \mathrm{H}_{2}$. These images show that the size of nanoparticles decreases with decreasing capturing temperature. On the other hand, Figure $5 \mathrm{~d}-\mathrm{f}$ show nanoparticles captured, respectively, at $900{ }^{\circ} \mathrm{C}, 600{ }^{\circ} \mathrm{C}$ and $300{ }^{\circ} \mathrm{C}$ at the gas mixture of $3 \% \mathrm{CH}_{4}-97 \% \mathrm{H}_{2}$. These images show that the size of nanoparticles increases with decreasing capturing temperature. To make a more quantitative analysis of the size, the size distribution of nanoparticles was measured from the TEM image.

Figure 6 shows the size distribution measured from 100 nanoparticles for each condition. At a gas mixture of $1 \% \mathrm{CH}_{4}-99 \% \mathrm{H}_{2}$, when the capture temperature decreased from $900{ }^{\circ} \mathrm{C}$ to $300{ }^{\circ} \mathrm{C}$, the average size of nanoparticles decreased from $\sim 4.5 \mathrm{~nm}$ to $\sim 3.2 \mathrm{~nm}$. At $3 \% \mathrm{CH}_{4}-97 \% \mathrm{H}_{2}$, however, when the capture temperature was decreased from $900{ }^{\circ} \mathrm{C}$ to $300{ }^{\circ} \mathrm{C}$, the average size increased from $\sim 3.1 \mathrm{~nm}$ to $\sim 3.8 \mathrm{~nm}$. The average size of $\mathrm{i}$-carbon nanoparticles was $\sim 3 \mathrm{~nm}$ regardless of the methane concentration and the capture temperature.

By comparing Figure 4 with Figure 6, it can be said that the average size of nanoparticles has a higher correlation with the number of $2.06 \AA$ than with the capture temperature. In other words, there is a high correlation that the larger the size the larger the number of cubic diamond and n-diamond and the smaller the size the larger the number of i-carbon. This result implies the possibility that the stability of the crystal structure of nanodiamonds should depend on the size.

In relation to this possibility, we made a literature survey on the dependence of the stability of nanodiamonds on the size. As the nanodiamond size decreases, the phase stability of the diamond also changes, and the nanodiamond becomes a more stable structure than the graphite phase [22,23]. From the results, the crystal structure of the nanoparticles would be related to the size of nanoparticles. According to a previous study on the size distribution of nanoparticles produced in the gas phase of a HFCVD diamond process via a Wien filter using differential pumping, the nanoparticles contained only $\sim 250$ carbon atoms at $1.5 \% \mathrm{CH}_{4}-98.5 \% \mathrm{H}_{2}$ [24]. These nanoparticles would be primary nanoparticles. The nanoparticles in Figure 5 are expected to form by coalescence of primary nanoparticles. 
Table 1. Comparison of the experimentally observed d-spacing values with those reported for cubic diamond, n-diamond, hexagonal diamond, and i-carbon

\begin{tabular}{|c|c|c|c|c|c|c|c|c|c|c|c|c|c|c|c|c|c|c|}
\hline \multicolumn{2}{|c|}{$\begin{array}{c}\text { Cubic } \\
\text { Diamond } \\
\text { (Observed) }\end{array}$} & \multicolumn{3}{|c|}{$\begin{array}{l}\text { Cubic Diamond } \\
\text { (JCPDS6-0675) }\end{array}$} & \multicolumn{2}{|c|}{$\begin{array}{l}\text { n-Diamond } \\
\text { (Observed) }\end{array}$} & \multicolumn{3}{|c|}{$\begin{array}{c}\text { n-Diamond } \\
\text { (JCPDS43-1104) }\end{array}$} & \multicolumn{2}{|c|}{$\begin{array}{l}\text { Hexagonal } \\
\text { Diamond } \\
\text { (Observed) }\end{array}$} & \multicolumn{3}{|c|}{$\begin{array}{l}\text { Hexagonal Diamond } \\
\text { (JCPDS19-0268) }\end{array}$} & \multicolumn{2}{|c|}{$\begin{array}{l}\text { i-Carbon } \\
\text { (Observed) }\end{array}$} & \multicolumn{2}{|c|}{ i-Carbon [18] } \\
\hline $\mathrm{d}(\AA)$ & $h k l$ & $\mathrm{~d}(\AA)$ & $h k l$ & $\mathrm{I} / \mathrm{I}_{111}$ & $\mathrm{~d}(\AA)$ & $h k l$ & $\mathrm{~d}(\AA)$ & $h k l$ & $\mathrm{I} / \mathrm{I}_{111}$ & $\mathrm{~d}(\AA)$ & $h k l$ & $\mathrm{~d}(\AA)$ & $h k l$ & $\mathrm{I} / \mathrm{I}_{111}$ & $\mathrm{~d}(\AA)$ & $h k l$ & $\mathrm{~d}(\AA)$ & $h k l$ \\
\hline & & & & & & & & & & 2.16 & 100 & 2.19 & 100 & 100 & 2.42 & 111 & 2.46 & 111 \\
\hline 2.06 & 111 & 2.06 & 111 & 100 & 2.06 & 111 & 2.06 & 111 & 100 & $\begin{array}{l}2.06 \\
1.93\end{array}$ & $\begin{array}{l}002 \\
101\end{array}$ & $\begin{array}{l}2.06 \\
1.92\end{array}$ & $\begin{array}{l}002 \\
101\end{array}$ & $\begin{array}{c}100 \\
50\end{array}$ & 2.10 & $200 *$ & 2.12 & $200^{*}$ \\
\hline & & & & & 1.78 & $200 *$ & 1.78 & $200 *$ & 100 & 150 & 102 & 150 & 102 & 25 & 1.73 & 211 & 1.74 & 211 \\
\hline 1.25 & 220 & 1.26 & 220 & 25 & 1.25 & 220 & 1.26 & 220 & 100 & 1.50 & 102 & $\begin{array}{l}1.50 \\
1.26 \\
1.17\end{array}$ & $\begin{array}{l}102 \\
110 \\
103\end{array}$ & $\begin{array}{l}25 \\
75 \\
50\end{array}$ & & & $\begin{array}{l}1.50 \\
1.28\end{array}$ & 311 \\
\hline & & 1.07 & 311 & 16 & & & 1.07 & 311 & 100 & & & 1.07 & 112 & 50 & & & & \\
\hline
\end{tabular}



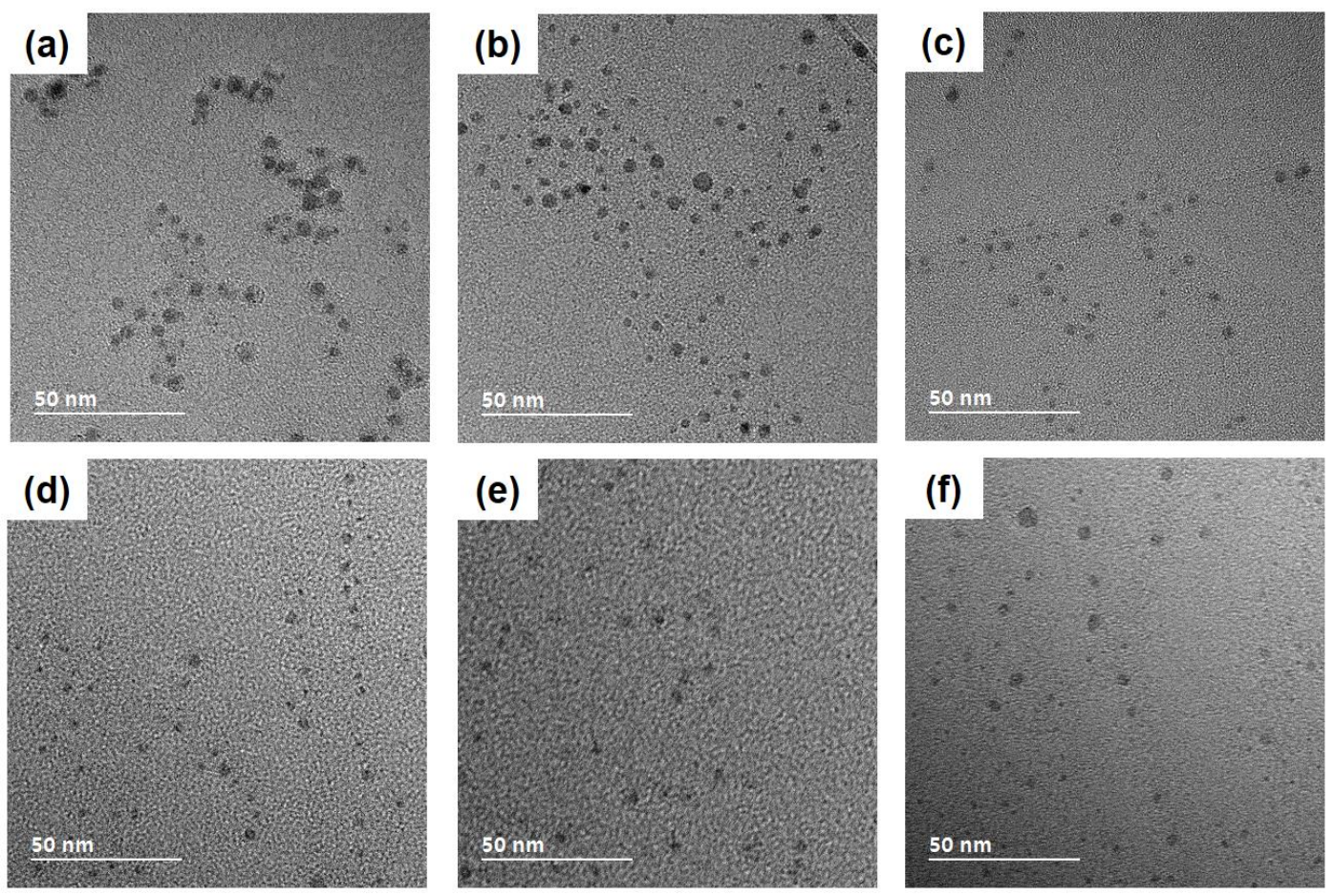

Figure 5. HR-TEM images of nanoparticles captured for $10 \mathrm{~s}$ using $1 \% \mathrm{CH}_{4}-99 \% \mathrm{H}_{2}$ at (a) $900{ }^{\circ} \mathrm{C}$, (b) $600{ }^{\circ} \mathrm{C}$, (c) $300{ }^{\circ} \mathrm{C}$ and using $3 \% \mathrm{CH}_{4}-97 \% \mathrm{H}_{2}$ at (d) $900{ }^{\circ} \mathrm{C}$, (e) $600{ }^{\circ} \mathrm{C}$, and (f) $300{ }^{\circ} \mathrm{C}$.
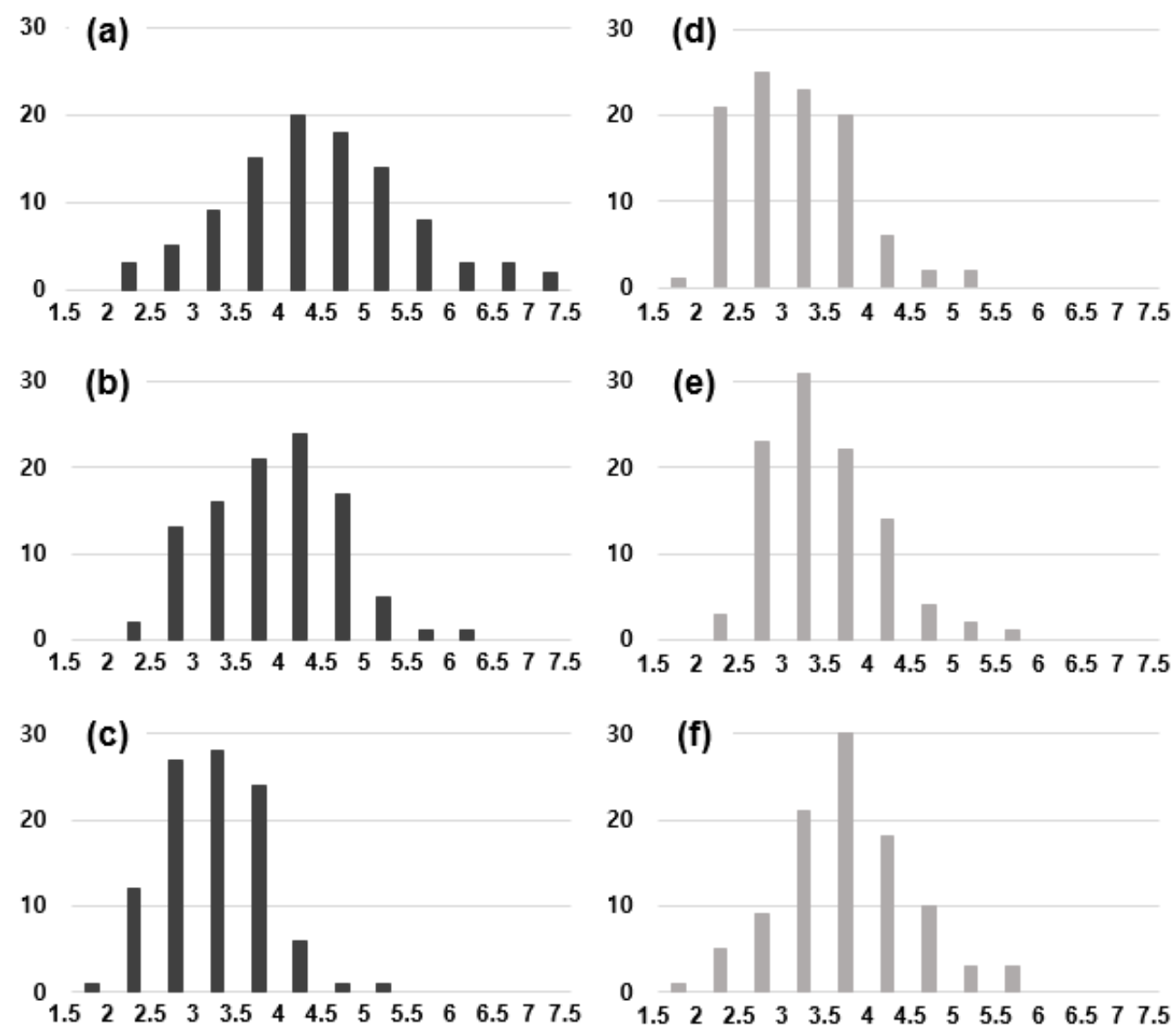

Figure 6. Distributions of the average size of 100 nanoparticles captured at $1 \% \mathrm{CH}_{4}-99 \% \mathrm{H}_{2}$ at (a) $900{ }^{\circ} \mathrm{C}$, (b) $600{ }^{\circ} \mathrm{C}$ and (c) $300{ }^{\circ} \mathrm{C}$ and captured at $3 \% \mathrm{CH}_{4}-97 \% \mathrm{H}_{2}$ at (d) $900{ }^{\circ} \mathrm{C}$, (e) $600{ }^{\circ} \mathrm{C}$ and (f) $300{ }^{\circ} \mathrm{C}$. 
The question is then, why are i-carbon nanoparticles mainly formed with $3 \% \mathrm{CH}_{4}-97 \% \mathrm{H}_{2}$ ? Moreover, why are cubic diamond and n-diamond nanoparticles more prevalent with $1 \% \mathrm{CH}_{4}-99 \%$ $\mathrm{H}_{2}$ ? Previously, Hwang et al. [25] suggested that the stability of diamond nanoparticles is promoted by the negative charge. To compare the amount of negative charge between the gas mixtures of $1 \%$ $\mathrm{CH}_{4}-99 \% \mathrm{H}_{2}$ and $3 \% \mathrm{CH}_{4}-97 \% \mathrm{H}_{2}$, we measured the current at the location $30 \mathrm{~mm}$ away from the hot filament at $2100{ }^{\circ} \mathrm{C}$ using the gas mixtures of $1 \% \mathrm{CH}_{4}-99 \% \mathrm{H}_{2}$ and $3 \% \mathrm{CH}_{4}-97 \% \mathrm{H}_{2}$. The current measured with $1 \% \mathrm{CH}_{4}-99 \% \mathrm{H}_{2}$ was $-24.9 \mu \mathrm{A} / \mathrm{cm}^{2}$, which was almost three-fold larger than that of $-8.3 \mu \mathrm{A} / \mathrm{cm}^{2}$ measured with $3 \% \mathrm{CH}_{4}-97 \% \mathrm{H}_{2}$. These negative currents would arise from electrons emitted from the hot filament. The thermionic emission depends on the work function of the hot filament. If the filament is coated with carbon, which is shown by the phase diagram calculated by Thermo-Calc [26] to occur at 3\% $\mathrm{CH}_{4}-97 \% \mathrm{H}_{2}$, the filament surface changes from tungsten carbide to graphite. Under these conditions, the work function would increase from $3.6 \mathrm{eV}$ for tungsten carbide [27] to $4.6 \mathrm{eV}$ for graphite [28], which could explain the three-fold discrepancy in the current readings. Relatively abundant electrons at $1 \% \mathrm{CH}_{4}-99 \% \mathrm{H}_{2}$ would tend to stabilize the $\mathrm{sp}^{3}$ bond of nanodiamond, which would result in cubic diamond or n-diamond. On the other hand, a relative deficiency in electrons at $3 \% \mathrm{CH}_{4}-97 \% \mathrm{H}_{2}$ would likely induce the $\mathrm{sp}^{2}$ bond of i-carbon $[29,30]$.

\subsection{Comparing the Captured Nanoparticles and Deposited Diamond}

To compare deposition behavior between the gas mixtures of $1 \% \mathrm{CH}_{4}-99 \% \mathrm{H}_{2}$ and $3 \% \mathrm{CH}_{4}-97 \%$ $\mathrm{H}_{2}$, a bare Si substrate without the pretreatment was used for deposition at $900{ }^{\circ} \mathrm{C}$ for $8 \mathrm{~h}$ under the same processing conditions as those under which the nanoparticles were captured. Figure 7 shows SEM images of diamond particles deposited on the Si substrate. Since the Si substrate was not pretreated, diamond particles instead of films were grown even after deposition for $8 \mathrm{~h}$. The diamond particles deposited using the gas mixture of $1 \% \mathrm{CH}_{4}-99 \% \mathrm{H}_{2}$ are shown in Figure 7 a with successively higher magnification images shown in Figure $7 \mathrm{~b}, \mathrm{c}$. The diamond particles deposited using the gas mixture of $3 \% \mathrm{CH}_{4}-97 \% \mathrm{H}_{2}$ are shown in Figure $7 \mathrm{~d}$, with a higher magnification image shown in Figure $7 \mathrm{e}$ and an even higher one shown in Figure $7 \mathrm{f}$.
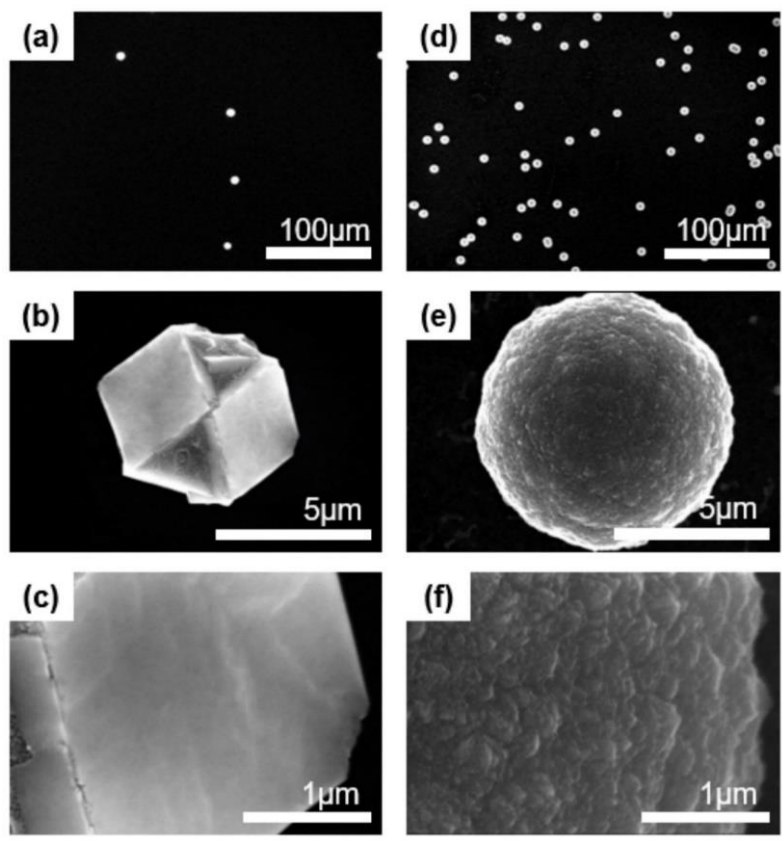

Figure 7. FE-SEM images of diamond deposited at (a) $1 \% \mathrm{CH}_{4}-99 \% \mathrm{H}_{2}$ and (d) $3 \% \mathrm{CH}_{4}-97 \% \mathrm{H}_{2}$ for $8 \mathrm{~h}$ on the bare silicon substrate. $(\mathbf{b}, \mathbf{e})$ are the higher magnification of $(\mathbf{a}, \mathbf{d})$, respectively, and $(\mathbf{c}, \mathbf{f})$ are the higher magnification of $(\mathbf{b}, \mathbf{e})$, respectively. 
The diamond particles in Figure 7a-c show well-developed (100) facets, whereas those in Figure $7 \mathrm{~d}-\mathrm{f}$ show ball-like or cauliflower-like structures with numerous nanosized nodules on the surfaces. The particle size in Figure $7 \mathrm{~b}$ is smaller than that shown in Figure 7e. When comparing the crystal structures of captured nanoparticles and diamond particles deposited for $8 \mathrm{~h}$, the nanoparticles captured at $1 \% \mathrm{CH}_{4}-99 \% \mathrm{H}_{2}$ were grown as well-faceted diamond particles, whereas the nanoparticles at $3 \% \mathrm{CH}_{4}-97 \% \mathrm{H}_{2}$ were grown as cauliflower diamond particles. These results suggest that the crystal structure of the nanoparticle affects the crystal structure of the deposited diamond.

\section{Conclusions}

About 600 nanoparticles captured in the HFCVD diamond process at various experimental conditions were analyzed by HR-TEM and FFT images and identified as cubic diamond, n-diamond, hexagonal diamond and i-carbon. The cubic diamond and n-diamond become more stable as the size increases and i-carbon becomes more stable as the size decreases in the size range of $2 \sim 7 \mathrm{~nm}$ of nanoparticles generated in the gas phase of HFCVD. Diamond crystals deposited for $8 \mathrm{~h}$ under the condition of the capture temperature of $900{ }^{\circ} \mathrm{C}$ and $1 \% \mathrm{CH}_{4}-99 \% \mathrm{H}_{2}$, where mainly cubic diamond and n-diamond nanoparticles were captured, have well-developed (100) facets, whereas diamond crystals deposited for $8 \mathrm{~h}$ under the condition of the capture temperature of $900{ }^{\circ} \mathrm{C}$ and $3 \% \mathrm{CH}_{4}-97 \%$ $\mathrm{H}_{2}$, where mainly i-carbon nanoparticles were captured, have ball-like or cauliflower-like structures.

Author Contributions: Conceptualization, H.-Y.K. and N.-M.H.; idea and experimental, H.-Y.K.; data interpretation, D.-S.K., K.-S.K. and H.-Y.K.; writing-original draft preparation, H.-Y.K.; writing —review and editing, H.-Y.K. and N.-M.H.; supervision, N.-M.H. All authors have read and agreed to the published version of the manuscript.

Funding: This work was supported by the National Research Foundation of Korea (NRF) grant funded by the Korea government (MSIT) (No. 2020R1A5A6017701), Global Frontier Program through the Global Frontier Hybrid Interface Materials (GFHIM) of the National Research Foundation of Korea (NRF) funded by the Ministry of Science, ICT \& Future Planning (MSIP) (No. 2013M3A6B1078874). This work was also supported by the Asian Office of Aerospace Research and Development (AOARD) (FA2386-15-1-4067).

Conflicts of Interest: The authors declare no conflict of interest.

\section{References}

1. Bundy, F.P.; Hall, H.T.; Strong, R.H. Man-made diamonds. Nature 1955, 176, 51-55. [CrossRef]

2. Deshpandey, C.V.; Bunshah, R.F. Diamond and diamondlike films: Deposition processes and properties. J. Vac. Sci. Technol. A 1989, 7, 2294-2302. [CrossRef]

3. Angus, J.C.; Will, H.A.; Stanko, W.S. Growth of diamond seed crystals by vapor deposition. J. Appl. Phys. 1968, 39, 2915-2922. [CrossRef]

4. Matsumoto, S.; Sato, Y.; Kamo, M.; Setaka, N. Vapor deposition of diamond particles from methane. Jpn. J. Appl. Phys. 1982, 21, L183. [CrossRef]

5. Dolmatov, V.Y. Detonation-synthesis nanodiamonds: Synthesis, structure, properties and applications. Russ. Chem. Rev. 2007, 76, 339-360. [CrossRef]

6. Yang, G.W.; Wang, J.B.; Liu, Q.X. Preparation of nano-crystalline diamonds using pulsed laser induced reactive quenching. J. Phys. Condens. Matter 1998, 10, 7923-7927. [CrossRef]

7. Pimenov, S.M.; Shafeev, G.A.; Smolin, A.A.; Konov, V.I.; Vodolaga, B.K. Laser-induced forward transfer of ultra-fine diamond particles for selective deposition of diamond films. Appl. Surf. Sci. 1995, 86, 208-212. [CrossRef]

8. Daulton, T.L.; Kirk, M.A.; Lewis, R.S.; Rehn, L.E. Production of nanodiamonds by high-energy ion irradiation of graphite at room temperature. Nucl. Instr. Meth. B 2001, 175, 12-20. [CrossRef]

9. Banhart, F.; Ajayan, P.M. Carbon onions as nanoscopic pressure cells for diamond formation. Nature 1996, 382, 433-435. [CrossRef]

10. Boudou, J.P.; Curmi, P.A.; Jelezko, F.; Wrachtrup, J.; Aubert, P.; Sennour, M.; Balasubramanian, G.; Reuter, R.; Thorel, A.; Gaffet, E. High yield fabrication of fluorescent nanodiamonds. Nanotechnology 2009, 20, 235602. [CrossRef] 
11. Galimov, É.M.; Kudin, A.M.; Skorobogatskii, V.N.; Plotnichenko, V.G.; Bondarev, O.L.; Zarubin, B.G.; Strazdovskii, V.V.; Aronin, A.S.; Fisenko, A.V.; Bykov, I.V.; et al. Experimental corroboration of the synthesis of diamond in the cavitation process. Dokl. Phys. 2004, 49, 150-153. [CrossRef]

12. Chang, Y.R.; Lee, H.Y.; Chen, K.; Chang, C.C.; Tsai, D.S.; Fu, C.C.; Lim, T.S.; Tzeng, Y.K.; Fang, C.Y.; Han, C.C.; et al. Mass production and dynamic imaging of fluorescent nanodiamonds. Nat. Nanotechnol. 2008, 3, 284-288. [CrossRef] [PubMed]

13. Greentree, A.D.; Fairchild, B.A.; Hossain, F.M.; Prawer, S. Diamond integrated quantum photonics. Mater. Today 2008, 11, 22-31. [CrossRef]

14. Vlasov, I.I.; Barnard, A.S.; Ralchenko, V.G.; Lebedev, O.I.; Kanzyuba, M.V.; Saveliev, A.V.; Konov, V.I.; Goovaerts, E. Nanodiamond photoemitters based on strong narrow-band luminescence from silicon-vacancy defects. Adv. Mater. 2009, 21, 808-812. [CrossRef]

15. Ōsawa, E. Recent progress and perspectives in single-digit nanodiamond. Diam. Relat. Mater. 2007, 16, 2018-2022. [CrossRef]

16. Turner, S.; Lebedev, O.L.; Shenderova, O.; Vlasov, I.I.; Verbeeck, J.; Tendeloo, G.V. Determination of size, morphology, and nitrogen impurity location in treated detonation nanodiamond by transmission electron microscopy. Adv. Funct. Mater. 2009, 19, 2116-2124. [CrossRef]

17. Park, J.W.; Kim, K.S.; Hwang, N.M. Gas phase generation of diamond nanoparticles in the hot filament chemical vapor deposition reactor. Carbon 2016, 106, 289-294. [CrossRef]

18. Vora, H.; Moravec, T.J. Structural investigation of thin films of diamondlike carbon. J. Appl. Phys. 1981, 52, 6151-6157. [CrossRef]

19. Peng, J.L.; Orwa, J.O.; Jiang, B.; Prawer, S.; Bursill, L.A. Nano-crystals of c-diamond, n-diamond and i-carbon grown in carbon-ion implanted fused quartz. Int. J. Mod. Phys. B 2001, 15, 3107-3123. [CrossRef]

20. Yamada, K.; Sawaoka, A.B. Very small spherical crystals of distorted diamond found in a detonation product of explosive/graphite mixtures and their formation mechanism. Carbon 1994, 32, 665-673. [CrossRef]

21. Bucknum, M.J.; Pickard, C.J.; Stamatin, I.; Castro, E.A. On the structure of i-carbon. J. Theor. Comput. Chem. 2006, 5, 175-185. [CrossRef]

22. Gamarnik, M.Y. Size-related stabilization of diamond nanoparticles. Nanostruct. Mater. 1996, 7, 651-658. [CrossRef]

23. Barnard, A.S.; Russo, S.P.; Snook, I.K. Coexistence of bucky diamond with nanodiamond and fullerene carbon phases. Phys. Rev. B 2003, 68, 073406. [CrossRef]

24. Jeon, I.D.; Park, C.J.; Kim, D.Y.; Hwang, N.M. Effect of methane concentration on size of charged clusters in the hot filament diamond CVD process. J. Cryst. Growth 2001, 223, 6-14. [CrossRef]

25. Hwang, N.M.; Hahn, J.H.; Yoon, D.Y. Charged cluster model in the low pressure synthesis of diamond. J. Cryst. Growth 1996, 162, 55-68. [CrossRef]

26. Sundman, B.; Jansson, B.; Andersson, J.O. The thermo-calc databank system. Calphad 1985, 9, $153-190$. [CrossRef]

27. Teng, F.; Wang, J.; An, X.; Lu, B.; Su, Y.; Gong, C.; Zhang, P.; Zhang, Z.; Xie, E. Single-phase tungsten carbide nanopillar arrays prepared by chemical vapor deposition. RSC Adv. 2012, 2, 7403-7405. [CrossRef]

28. Krishnan, K.S.; Jain, S.C. Thermionic constants of graphite. Nature 1952, 169, 702-703. [CrossRef]

29. Park, N.J.; Park, S.G.; Hwang, N.M.; Ihm, J.S.; Tejima, S.; Nakamura, H. First-principles study of the effect of charge on the stability of a diamond nanocluster surface. Phys. Rev. B 2004, 69, 195411. [CrossRef]

30. Lai, L.; Barnard, A.S. Charge-induced restructuring and decomposition of bucky-diamonds. J. Mater. Chem. 2012, 22, 13141-13147. [CrossRef]

Publisher's Note: MDPI stays neutral with regard to jurisdictional claims in published maps and institutional affiliations.

(C) 2020 by the authors. Licensee MDPI, Basel, Switzerland. This article is an open access article distributed under the terms and conditions of the Creative Commons Attribution (CC BY) license (http://creativecommons.org/licenses/by/4.0/). 